\title{
Prognostic value of programmed cell death ligand-1 expression in the tumor-infiltrating immune cells of patients with lung cancer: A meta-analysis
}

\author{
BIRHANU ABERHA BERELE, GUIFANG YANG and TI WU \\ Department of Pathology, Zhongnan Hospital of Wuhan University, Wuhan, Hubei 430071, P.R. China
}

Received December 19, 2020; Accepted June 7, 2021

DOI: $10.3892 / \operatorname{mco} .2021 .2329$

\begin{abstract}
Several studies have investigated the prognostic significance of programmed cell death ligand 1 (PD-L1)positive expression in the tumor cells (TC) of patients with lung cancer. However, tumor-infiltrating immune cell (TIIC)-based PD-L1 expression and its prognostic value remain controversial. The present meta-analysis was performed on 11 studies comprising 2,685 patients, which were identified by a systematic search on the PubMed, PMC, Web of Science and Embase databases. The databases were searched for published articles up to October 30, 2020. The studies that evaluated overall survival (OS) or disease-free survival (DFS) expressed as hazard ratios (HRs) in the PD-L1 TIIC of patients with lung cancer were analyzed. All statistical analyses were conducted using Stata software, version 16.0. The results demonstrated that PD-L1 expression in TIICs was not associated with OS $[\mathrm{HR}=0.98$; confidence interval $(\mathrm{CI})=0.73-1.33 ; \mathrm{P}=0.53]$ and $\mathrm{DFS}(\mathrm{HR}=1.05$; $\mathrm{CI}=0.63-1.77 ; \mathrm{P}=0.42$ ) for all the cohort included in the study. However, subgroup analysis revealed that PD-L1 TIICs were associated with improved $O S$ in lung squamous cell carcinoma ( $\mathrm{HR}=0.76 ; \mathrm{CI}=0.58-0.99 ; \mathrm{P}=0.04)$, while poorer $\mathrm{DFS}$ was observed in lung adenocarcinoma $(\mathrm{HR}=1.30 ; \mathrm{CI}=1.19-1.43$; $\mathrm{P}=0.008)$ and at the $>1 \%$ staining cutoff value $(\mathrm{HR}=1.56$; $\mathrm{CI}=1.12-2.16 ; \mathrm{P}=0.03)$. However, poor OS $(\mathrm{P}=0.21)$ and $\mathrm{DFS}$ $(\mathrm{P}=0.14)$ were observed in Asian populations, while DFS $(\mathrm{P}=0.07)$ for only-membrane staining was not statistically significant. The results of the present study suggested that adding PD-L1 TIICs to the existing diagnostic algorithm may
\end{abstract}

Correspondence to: Professor Guifang Yang, Department of Pathology, Zhongnan Hospital of Wuhan University, 169 East Lake Road, Wuchang, Wuhan, Hubei 430071, P.R. China

E-mail: YangGF@whu.edu.cn

Abbreviations: PD-L1, programmed cell death ligand-1; TIIC, tumor infiltrating immune cells; OS, overall survival; DFS, disease free survival; HR, hazard ratio; IHC, immunohistochemistry

Key words: programmed cell death ligand 1, tumor-infiltrating immune cell, prognosis, meta-analysis, lung cancer help to guide patient selection for anti-PD-1/PD-L1 therapy. Future large-scale studies are warranted for confirmation of the present findings.

\section{Introduction}

As the malignant tumor with highest morbidity and mortality, lung cancer remains a global major public health problem (1). In contrast to a steady increase in the survival of the majority of tumors, advances in lung cancer have been slow, and its 5-year relative survival rate is still $\sim 19 \%$ (1). This may be attributed to the unsatisfactory efficacy of traditional treatments such as chemotherapy, radiotherapy and tumorectomy, particularly at advanced stages of the disease (2). Therefore, the introduction of immunotherapy targeting immune checkpoint molecules, such as programmed cell death ligand 1 (PD-L1), into clinical practice has recently gained increasing attention (3). Since PD-L1 expression on tumor cells (TC) is the mechanism by which TC could escape immune system surveillance, its expression is not only linked to the response of immune checkpoint therapy, but is also correlated with the prognosis of non-small cell lung cancer (NSCLC) $(4,5)$. PD-L1, the predominant ligand for PD-1, can be expressed in multiple tissues, including tumor-infiltrating $\mathrm{T}$ and $\mathrm{B}$ lymphocytes, dendritic cells and other immune cells $(5,6)$. To date, all previous meta-analyses have identified PD-L1 expression on TC as a putative prognostic biomarker in NSCLC (7-9). However, meta-analyses of the prognostic significance of PD-L1 in tumor-infiltrating immune cells (TIICs) have not yet been conducted. Recent clinical trials have revealed that higher response rate to $\mathrm{PD}-1 / \mathrm{PD}-\mathrm{L} 1$ targeted therapy was associated with positive expression of PDL-1 in TIICs $(10,11)$. This suggests that, in addition to using tumor cell-based PD-L1 expression, immune cell-based PD-L1 expression may be clinically relevant. Although a number of studies have reported the prognostic significance of PD-L1 expression on TIICs in lung cancer, the findings remain controversial.

The aim of the present study was to conduct a metaanalysis and to evaluate the prognostic value of PD-L1-positive expression in TIICs, which was expressed as the hazard ratio (HR) for overall survival (OS) and disease-free survival (DFS) in patients with lung cancer. 


\section{Materials and methods}

Search strategy. For study search and selection, the recommendation (12) of the Preferred Reporting Items for Systematic Reviews and Meta-Analyses (PRISMA) guidelines were followed. Relevant articles were retrieved from the electronic databases of PubMed, PMC, Embase and Web of Science. Studies published before October 30, 2020 were screened by their title and abstract. The key words used in the search strategy were 'PD-L1 OR PD-L1 OR B7-H1 OR C274' AND 'tumor-infiltrating lymphocytes OR TIL OR tumor infiltrating immune cells OR TIIC' AND 'lung' AND 'cancer OR carcinoma OR neoplasm OR tumor' AND 'survival OR prognosis. A manual search for references cited in the retrieved articles on the topic was also conducted.

Inclusion and exclusion criteria. Studies were considered eligible if they met the following criteria: i) Studies on patients with lung cancer in whom PD-L1 expression on TIICs was determined by immunohistochemistry (IHC); ii) studies reporting the prognostic value of PD-L1 on TIICs alongside OS and/or DFS, and HR with 95\% confidence interval (CI); iii) and studies reporting sufficient data to calculate or extract HR values, such as Kaplan-Meier (KM) survival curves, were included in the meta-analysis.

Articles were excluded from the meta-analysis if they met the following criteria: i) The articles were conference abstracts, reviews or case studies; or ii) contained insufficient data to calculate or extract HR, or if KM information was not available; or) were not written in English.

Data extraction and quality assessment. Data extraction was performed by two authors using a predesigned data extraction form. The following data were extracted from eligible studies: Name of first author, publication year, country, subtype of lung cancer, number of patients, format of pathological section, tumor stage, IHC evaluation methods, antibody clones used for PD-L1 detection and positive cutoff value for expression of PD-L1 on TIICs.

Quality assessment of the included studies was performed by Newcastle-Ottawa scale. Studies that scored $\geq 6$ points were considered to have a high quality.

Statistical analysis. Survival data were primarily extracted as HR and 95\% CI. When studies reported HR of Cox univariate and multivariate analyses, the HR of Cox multivariate analysis was used, since it is good for situation with missing outcomes and usually leads to more precise conclusion. If HR was not directly available in the article, it was calculated from available data or extracted from the KM survival curve using WebPlotDigitizer (13). Statistical heterogeneity was assessed by $\chi^{2}\left(\mathrm{I}^{2}\right)$ and visual inspection of the forest plot. $\mathrm{I}^{2}>50 \%$ was considered to indicate the presence of heterogeneity. The random-effects model was used due to the presence of heterogeneous studies. To identify the source of heterogeneity and evaluate the influence of different adjustment factors or confounders, subgroup analysis was performed. Funnel plotswere used to estimate publication bias and small-study effects. HR $>1$ and $\mathrm{HR}<1$ indicated poor and improved prognosis, respectively, while
$\mathrm{HR}=1$ considered no effect. For all analyses, Stata software, version 16.0 was used. $\mathrm{P}<0.05$ was considered to indicate a statistically significant difference.

\section{Results}

Search results and study characteristics. The search was completed in October 2020. The detailed flow diagram for screening studies that identified a total of 8,311 search records is shown in Fig. 1. EndNote software, version $\mathrm{X} 7$ was used to identify duplicates and to manage citations. According to the established inclusion and exclusion criteria, and by thoroughly reviewing articles, 11 studies (2,685 patients) were included in the final analysis using the Preferred Reporting Items for Systematic Reviews and Meta-Analyses flow diagram (12) for identified articles. The characteristics of the included studies are summarized in Tables I and II.

Among the included studies, $8(11,14-20)$ were focused on non-small cell lung cancer (NSCLC), of which, 1 study was on pulmonary squamous cell carcinoma (14) and 1 on lung adenocarcinoma (16). The remaining studies were on pulmonary neuroendocrine carcinoma $(21,22)$ and SCLC $(23)$. All studies assessed PD-L1 expression on TIICs using IHC. In total, 7 different types of monoclonal antibody were used, among which, SP142 clone was used in 4 studies $(11,15,17,21)$ while the other antibodies were used once. A total of 4 studies $(17,19,21,22)$ defined membranous and/or cytoplasmic staining of PDL-1 in TIICs as positive, whereas 5 studies $(14,15,20,23,24)$ considered positive expression only the cases with membranous staining of PD-L1 in TIICs. The cutoff values for evaluating the positive expression of PD-L1 in TIICs were divided into two types: i) Proportion of stained cells $\geq 5 \%$ and ii) proportion of stained cells $\geq 1 \%$. While 9 studies $(11,15,16,19-23)$ used $1 \%$ cutoff value for evaluation, only 2 studies $(14,17)$ used $5 \%$ cutoff value for evaluation. In 10 of 11 studies, whole slides (11,14-17,20-23) were used for evaluating cancer samples, while only 1 study used tissue microarray assay (19). Among the included studies, 3 were prospective cohort studies, 7 were retrospective cohort studies and 1 was a randomized control trial study (RCT).

$P D-L 1$ expression and $O S$. The pooled result of 9 studies did not reveal a statistically significant association between PD-L1 expression in TIICs and OS (HR=0.98, CI=0.73-1.33, $\mathrm{P}=0.53$; Fig. 2A). This may be attributed to the presence of heterogeneity among all the included studies.

Subgroup analysis between PD-L1 TIIC expression and $O S$. To identify the source of heterogeneity, subgroup analysis in subtypes of lung cancer, cutoff values, ethnicity, study design and staining localization was conducted. Lung squamous cell carcinoma was associated with improved prognosis $(\mathrm{HR}=0.76, \mathrm{CI}=0.58-0.99, \mathrm{P}=0.04$; Fig. 3A). However, PD-L1 expression in TIICs assessed by $\geq 1 \%$ cutoff value $(\mathrm{P}=0.48)$ and $\geq 5 \%$ cutoff value $(\mathrm{P}=0.38)$ was not significantly associated with OS ( $\mathrm{P}=0.53)$ (Fig. 4A). Although Asian ethnicity $(\mathrm{P}=0.21)$ and membrane-only staining $(\mathrm{P}=0.21)$ tended tobe associated with worse OS, the association was not statistically significant 
Table I. Characteristics of the studies included in the present meta-analysis.

\begin{tabular}{|c|c|c|c|c|c|c|}
\hline Author (year) & Country & Subtype of lung cancer & Stage & $\begin{array}{l}\text { Number of } \\
\text { patients }\end{array}$ & $\begin{array}{l}\text { Age, median } \\
\text { years (range) }\end{array}$ & (Refs.) \\
\hline Fehrenbacher et al (2016) & USA & NSCLC & NR & 86 & NR & (11) \\
\hline Yang et al (2016) & China & $\begin{array}{l}\text { NSCLC (Squamous cell } \\
\text { carcinoma) }\end{array}$ & I & 105 & $40-85$ & (14) \\
\hline Theelen et al (2019) & Netherlands & NSCLC & I-IV & 286 & NR & (15) \\
\hline Mignon et al (2020) & Belgium & Adenocarcinoma & I-III & 237 & NR & (16) \\
\hline Vallonthaiel et al (2017) & India & NSCLC & $1-\mathrm{IV}$ & 62 & $58(29-78)$ & (17) \\
\hline Chen et al (2109) & China & NSCLC & I-IV & 234 & NR & (18) \\
\hline Paulsen et al (2017) & Norway & NSCLC & I-IIIA & 505 & $67(28-85)$ & (19) \\
\hline Sumitomo et al (2019) & Japan & NSCLC & I-III & 160 & NR & $(20)$ \\
\hline Wang et al (2018) & China & $\begin{array}{l}\text { Pulmonary neuroendocrine } \\
\text { tumors }\end{array}$ & I-III & 159 & $59.5(30-83)$ & $(21)$ \\
\hline Kim et al (2018) & Korea & $\begin{array}{l}\text { High-grade neuroendocrine } \\
\text { carcinoma }\end{array}$ & I-IV & 192 & $66(36-89)$ & (22) \\
\hline Bonanno et al (2018) & Italy & Small cell lung cancer & I-IV & 104 & $69(47-86)$ & (23) \\
\hline
\end{tabular}

NSCLC, non-small cell lung cancer; NR, not reported.

Table II. Assessment methods of the included studies.

\begin{tabular}{|c|c|c|c|c|c|c|c|c|}
\hline Study & $\begin{array}{l}\text { Tissue } \\
\text { slides }\end{array}$ & Antibody & $\begin{array}{l}\text { Staining } \\
\text { location }\end{array}$ & $\begin{array}{l}\text { Median } \\
\text { follow up } \\
\text { (months) }\end{array}$ & Outcome & $\begin{array}{c}\text { PD-L1 } \\
\text { TIIC cutoff } \\
\text { value }(\%)\end{array}$ & $\begin{array}{c}\text { NOS } \\
\text { quality } \\
\text { assessment }\end{array}$ & (Refs.) \\
\hline Fehrenbacher et al (2016) & Whole slide & SP142 & NR & 15 & OS & 1 & 7 & (11) \\
\hline Yang et al (2016) & Whole slide & NR & Membrane & 79 & $\begin{array}{c}\text { OS and } \\
\text { DFS }\end{array}$ & 5 & 6 & (14) \\
\hline Theelen et al (2019) & Whole slide & SP142 & Membrane & 96 & OS & 1 & 6 & $(15)$ \\
\hline Mignon et al (2020) & Whole slide & NR & NR & NR & OS & 1 & 6 & (16) \\
\hline Vallonthaiel et al (2017) & Whole slide & SP142 & $\begin{array}{l}\text { Membrane/ } \\
\text { cytoplasm }\end{array}$ & 16 & DFS & 5 & 7 & (17) \\
\hline Chen et al (2109) & Whole slide & E1L3N & Membrane & NR & DFS & 1 & 6 & $(18)$ \\
\hline Paulsen et al (2017) & $\begin{array}{l}\text { Tissue } \\
\text { microarray }\end{array}$ & E1L3N & $\begin{array}{l}\text { Membrane/ } \\
\text { cytoplasm }\end{array}$ & NR & $\begin{array}{l}\text { OS and } \\
\text { DFS }\end{array}$ & 1 & 7 & (19) \\
\hline Sumitomo et al (2019) & Whole slide & SP263 & Membrane & 42.8 & $\begin{array}{l}\text { OS and } \\
\text { DFS }\end{array}$ & 1 & 6 & (20) \\
\hline Wang et al (2018) & Whole slide & SP142 & $\begin{array}{l}\text { Membrane/ } \\
\text { cytoplasm }\end{array}$ & NR & OS & 1 & 6 & $(21)$ \\
\hline Kim et al (2018) & Whole slide & NR & $\begin{array}{l}\text { Membrane/ } \\
\text { cytoplasm }\end{array}$ & 80.7 & OS & 1 & 7 & $(22)$ \\
\hline Bonanno et al (2018) & Whole slide & $22 \mathrm{C} 3$ & Membrane & 13.4 & OS & 1 & 6 & $(23)$ \\
\hline
\end{tabular}

PD-L1, programed cell death ligand 1; TIIC, tumor infiltrating immune cells; NR, not reported; OS, overall survival; DFS, disease free survival; NOS, Newcastle-Ottawa scale.

(Figs. 5A and 6A, respectively). Subgroup analysis by research design revealed that prospective cohort studies tended to be associated with better prognosis $(\mathrm{HR}=0.79$,
$\mathrm{CI}=0.21-2.96, \mathrm{P}=0.24)$, while retrospective cohort studies had a borderline effect $(\mathrm{HR}=1.07, \mathrm{CI}=0.79-1.45, \mathrm{P}=0.36)$, although neither design exhibited a statistically significant 


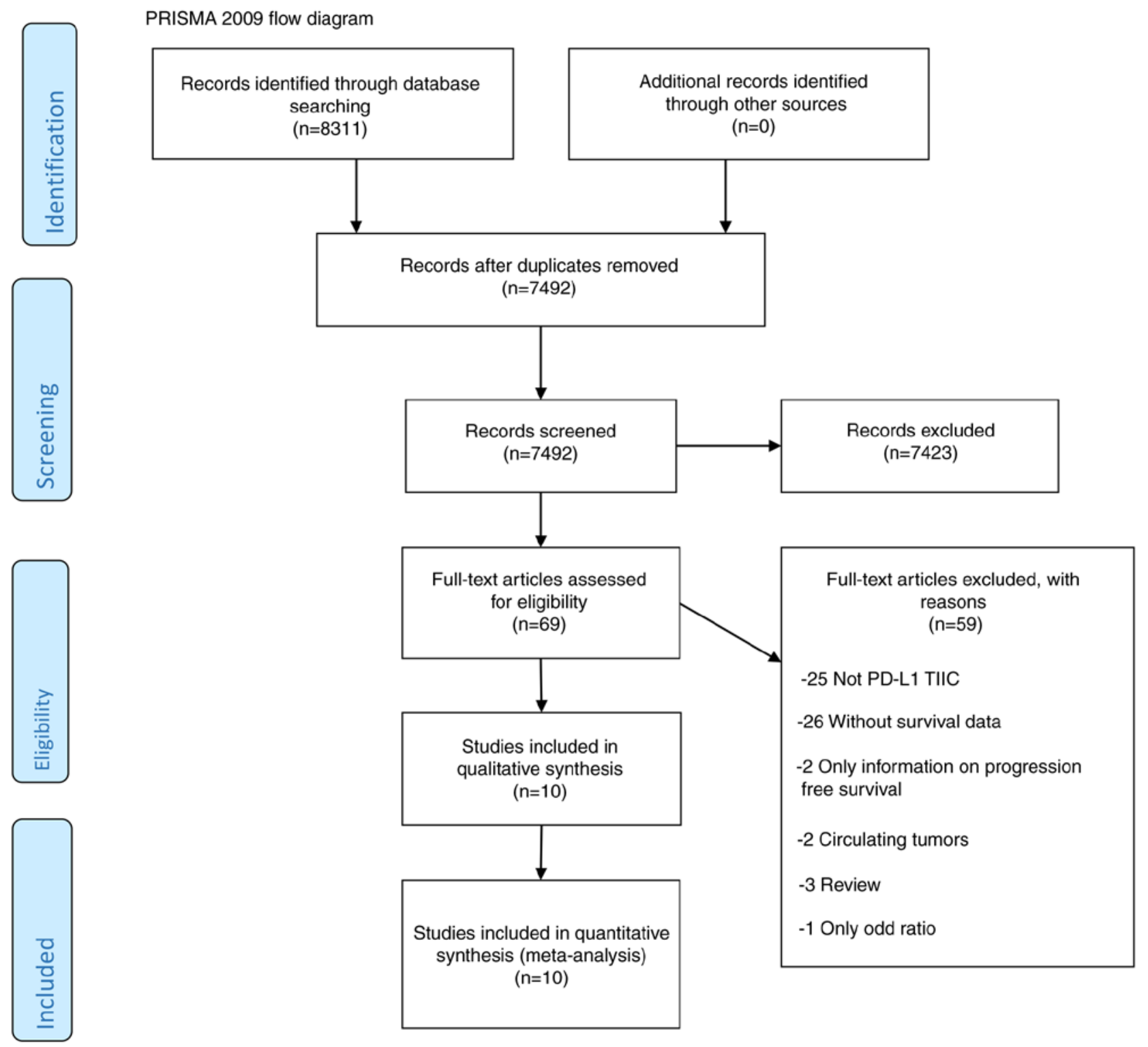

Figure 1. PRISMA flow diagram presenting the retrieved articles for the current review ( $\mathrm{n}=11)$. PRISMA, Preferred Reporting Items for Systematic Reviews and Meta-Analyses; PD-L1, programed cell death ligand 1; TIIC, tumor infiltrating immune cells.

difference (Fig. 7). Only a randomized control study that demonstrated improved survival was reported. Excluding this RCT study design from all other study designs did not alter the meta-analysis pooled result. Furthermore, funnel plot testing for publication bias showed that there were no small-study effects for OS (Fig. 8).

PD-L1 expression in TIICs and DFS. Only 5 studies were investigated the pooled results of which did not show a statistically significant association between PD-L1 TIIC and DFS (HR=1.05, $\mathrm{CI}=0.63-1.77, \mathrm{P}=0.42$; Fig. 2B). This result may be due to the presence of heterogeneity.

Subgroup analysis between PD-L1 TIIC expression and DFS. Subgroup analysis showed that PD-L1 TIIC expression in pulmonary adenocarcinoma $(\mathrm{HR}=1.30, \mathrm{CI}=1.19-1.43$, $\mathrm{P}=0.008)$ and assessment by $\geq 1 \%$ staining cutoff value $(\mathrm{HR}=1.56, \mathrm{CI}=1.12-2.16, \mathrm{P}=0.03)$ exhibited an opposite survival trend (Figs. 3B and 4B, respectively). Although Asian ethnicity $(\mathrm{P}=0.14)$ and membrane-only staining appeared to be poor predictors of prognosis $(\mathrm{P}=0.07)$, the correlation was not statistically significant (Figs. 5B and 6B, respectively).

\section{Discussion}

A number of meta-analyses (25-29) demonstrated that PD-L1 expression on $\mathrm{TC}$ is becoming a powerful prognostic tool in guiding patient selection for PD-1/PD-L1 inhibitor therapy in various cancer types, including lung cancer. To the best of our knowledge, the present study is the first meta-analysis to assess the prognostic value of PD-L1 expression in TIICs in patients with lung cancer. Here, 10 of 11 included studies in the meta-analysis were observational studies. As univariate analysis data are difficult for clinical interpretation in observational studies, multivariate model was used as this model usually 


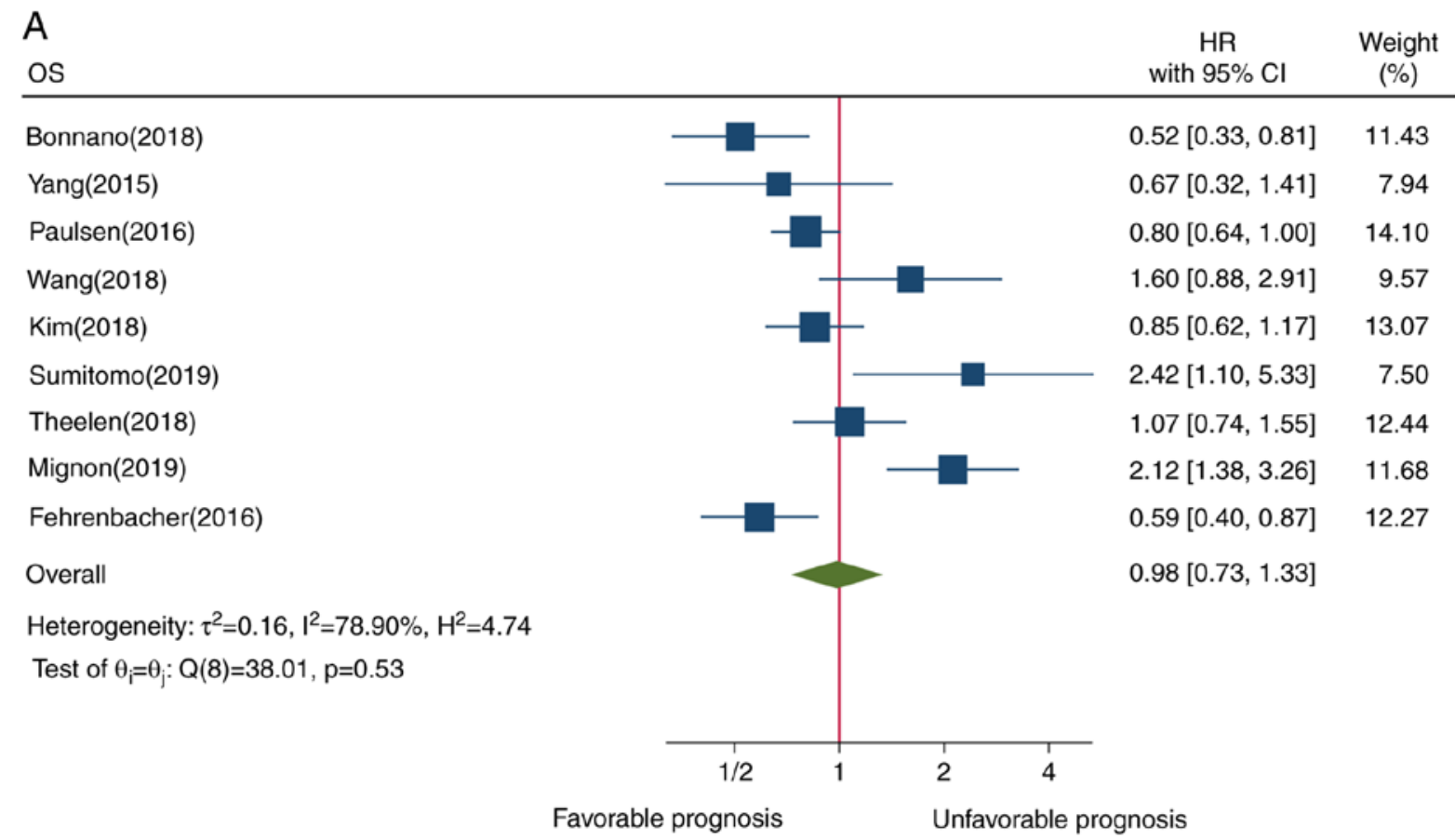

Random-effects DerSimonian-Laird model

avorable prognosis Unfavorable prognosis

B

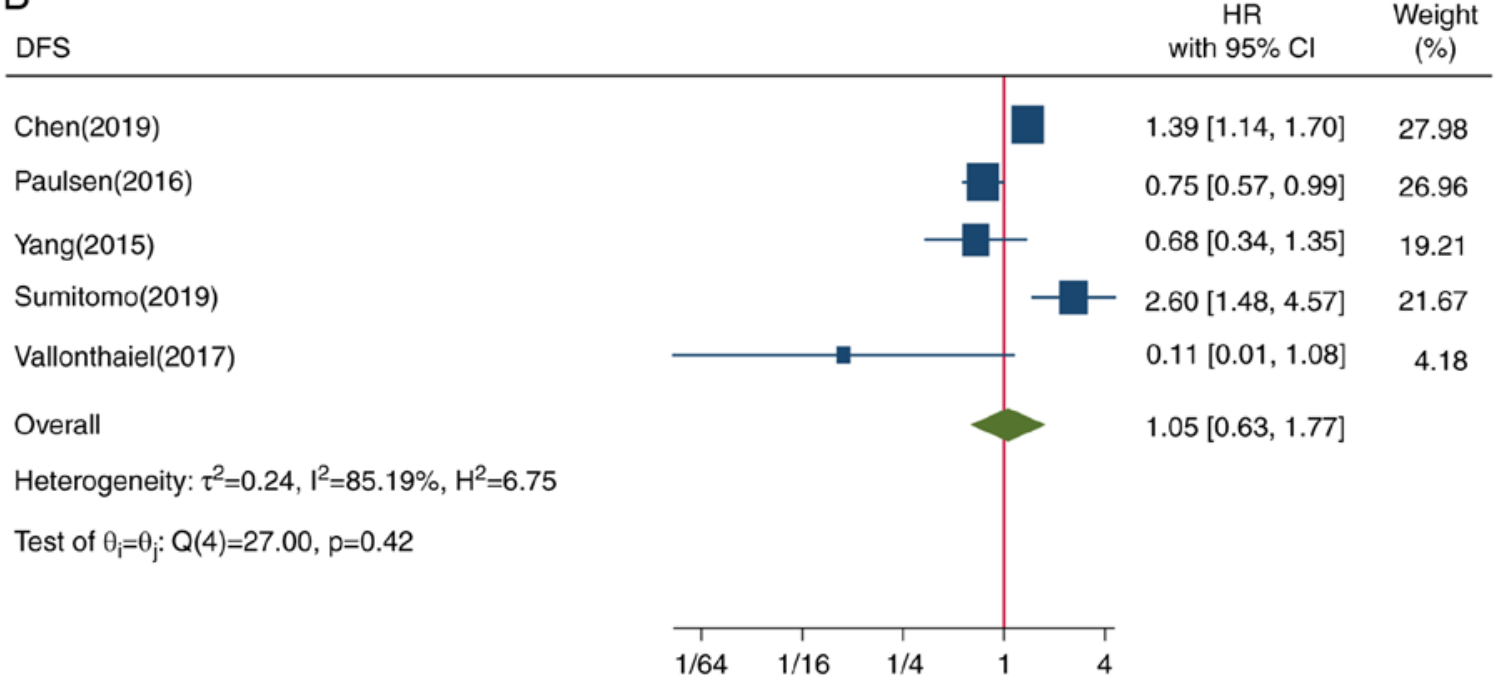

Random-effects DerSimonian-Laird model

Favorable prognosis Unfavorable prognosis

Figure 2. Forest plot presenting the relationship between PD-L1 TIIC and lung cancer prognosis for all included studies. (A) OS and (B) DFS in PD-L1 TIIC. PD-L1, programmed cell death ligand 1; TIIC, tumor infiltrating immune cells; OS, overall survival; DFS, disease free survival; HR, hazard ratio; CI, confidence interval.

leads to more precise conclusion. There were three studies that reported both univariate and multivariate results. Interestingly, in these studies, the difference between univariate and multivariate result was small and statistical/clinical conclusions didn't change.

The overall pooled result showed that PD-L1 expression in TIICs was not associated with OS or DFS in any of the included populations with lung cancer. This finding is consistent with a meta-analysis of the included cancer types (30), and with the results reported in tumors of the digestive system (6), as well as cohort studies $(31,32)$. However, the present result contradicts previous studies that revealed that PD-L1 TIIC in primary breast cancer (26) was associated with improved OS, while in SCLC (33) and in head and neck cancer (34) it was associated with longer DFS. The differences in the definition of PD-L1 positivity, cancer type, IHC methods used, therapeutic regimen and other clinicopathological variables may account for the contradictory results. Additionally, the differences in primary endpoint outcome may also be another source of variation: While the present study used OS and DFS, other studies $(33,34)$ reported relapse-free survival as the primary endpoint outcome. 
A

\section{OS}

Adenocarcinoma

Mignon(2019)

Paulsen(2016)

Heterogeneity: $\tau^{2}=0.60, \mathrm{I}^{2}=95.47 \%, \mathrm{H}^{2}=22.10$

Test of $\theta_{i}=\theta_{j}: Q(1)=22.10, p=0.62$

Squamous cell carcinoma

Paulsen(2016)

Yang(2015)

Heterogeneity: $\tau^{2}=0.23, \mathrm{I}^{2}=47 \%, \mathrm{H}^{2}=1.00$

Test of $\theta_{\mathrm{i}}=\theta_{\mathrm{j}}: \mathrm{Q}(1)=0.11, \mathrm{p}=0.04$

Overall

Heterogeneity: $\tau^{2}=0.19, \mathrm{I}^{2}=86.61 \%, \mathrm{H}^{2}=7.49$

Test of $\theta_{i}=\theta_{j}: Q(3)=22.48, p=0.45$

Random-effects DerSimonian-Laird model
HR Weight

with $95 \% \mathrm{Cl}$

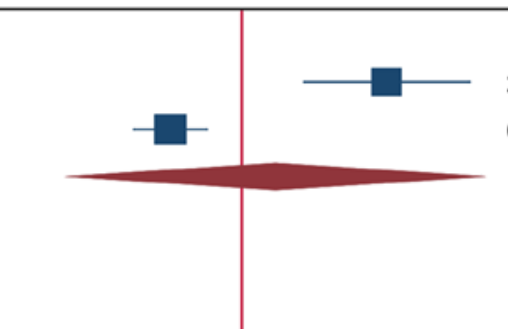

$2.12[1.38,3.26] \quad 24.78$

$0.69[0.57,0.83] \quad 29.70$

$1.19[0.40,3.57]$

$0.77[0.58,1.03] \quad 27.95$

$0.67[0.32,1.41] \quad 17.57$

$0.76[0.58,0.99]$

$0.94[0.58,1.50]$

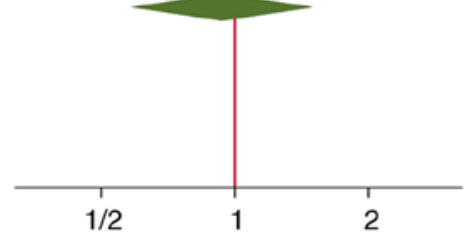

Unfavorable prognosis

$B$ DFS

$\mathrm{HR}$

with $95 \% \mathrm{Cl}$
Weight (\%)

Adenocarcinoma
Paulsen(2016)
Chen(2019)
Sumitomo(2019)
Heterogeneity: $\tau^{2}=0.16, \mathrm{I}^{2}=26 \%, \mathrm{H}^{2}=1.00$
Test of $\theta_{\mathrm{i}}=\theta_{\mathrm{j}}: \mathrm{Q}(2)=0.51, \mathrm{p}=0.008$
Squamous cell carcinoma
Paulsen(2016)
Heterogeneity: $\tau^{2}=0.01, \mathrm{I}^{2}=10.2 \%, \mathrm{H}^{2}=0.8$
Test of $\theta_{\mathrm{i}}=\theta_{\mathrm{j}}: \mathrm{Q}(0)=1.7, \mathrm{p}=0.002$
Overall
Heterogeneity: $\tau^{2}=0.06, \mathrm{I}^{2}=80.30 \%, \mathrm{H}^{2}=5.08$
Test of $\theta_{\mathrm{i}}=\theta_{\mathrm{j}}: \mathrm{Q}(3)=15.23, \mathrm{p}=0.14$

Random-effects DerSimonian-Laird model

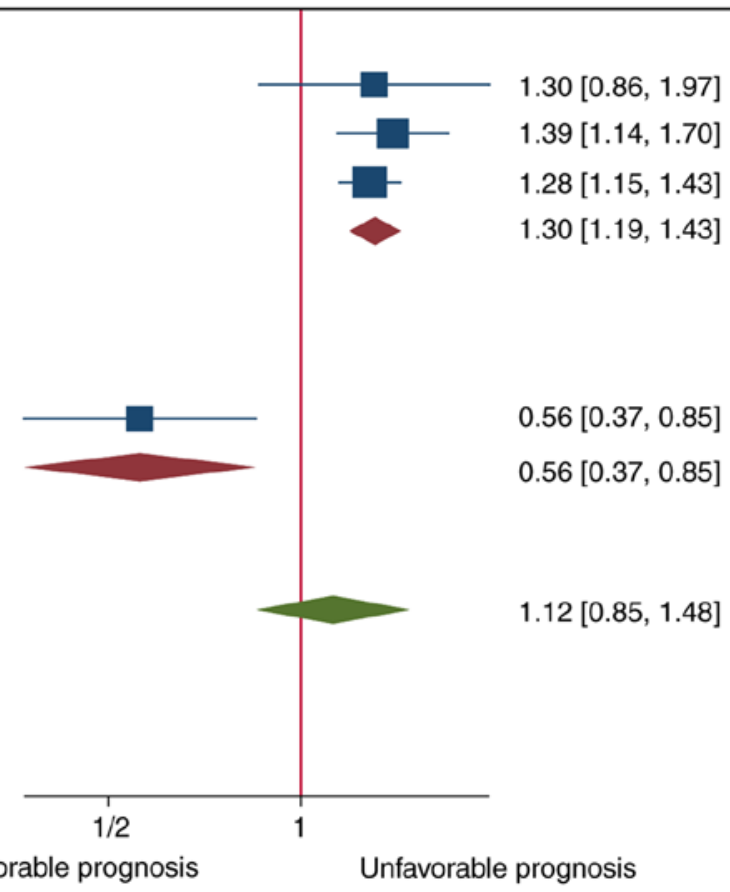

Figure 3. Forest plot showing the relationship between PD-L1 TIIC and prognosis by subtype of lung cancer. (A) OS and (B) DFS for patients with lung adenocarcinoma and squamous cell carcinoma. PD-L1, programmed cell death ligand 1; TIIC, tumor infiltrating immune cells; OS, overall survival; DFS, disease free survival; HR, hazard ratio; CI, confidence interval.

In the present meta-analysis, due to the presence of heterogeneity, subgroup analysis was performed by subtype of lung cancer, cutoff value, ethnicity and staining localization in order to identify the source of heterogeneity.

As regards tumor subtype, the present results showed that PD-L1 TIIC overexpression in adenocarcinoma was associated with poor DFS. This finding is consistent with a meta-analysis (35) and a cohort study (36) on PD-L1 in TC in pulmonary adenocarcinoma. However, the present study demonstrated that PD-L1 TIIC expression was associated with improved OS for patients with pulmonary squamous cell carcinoma. This indicates that the presence of a heterogeneous 


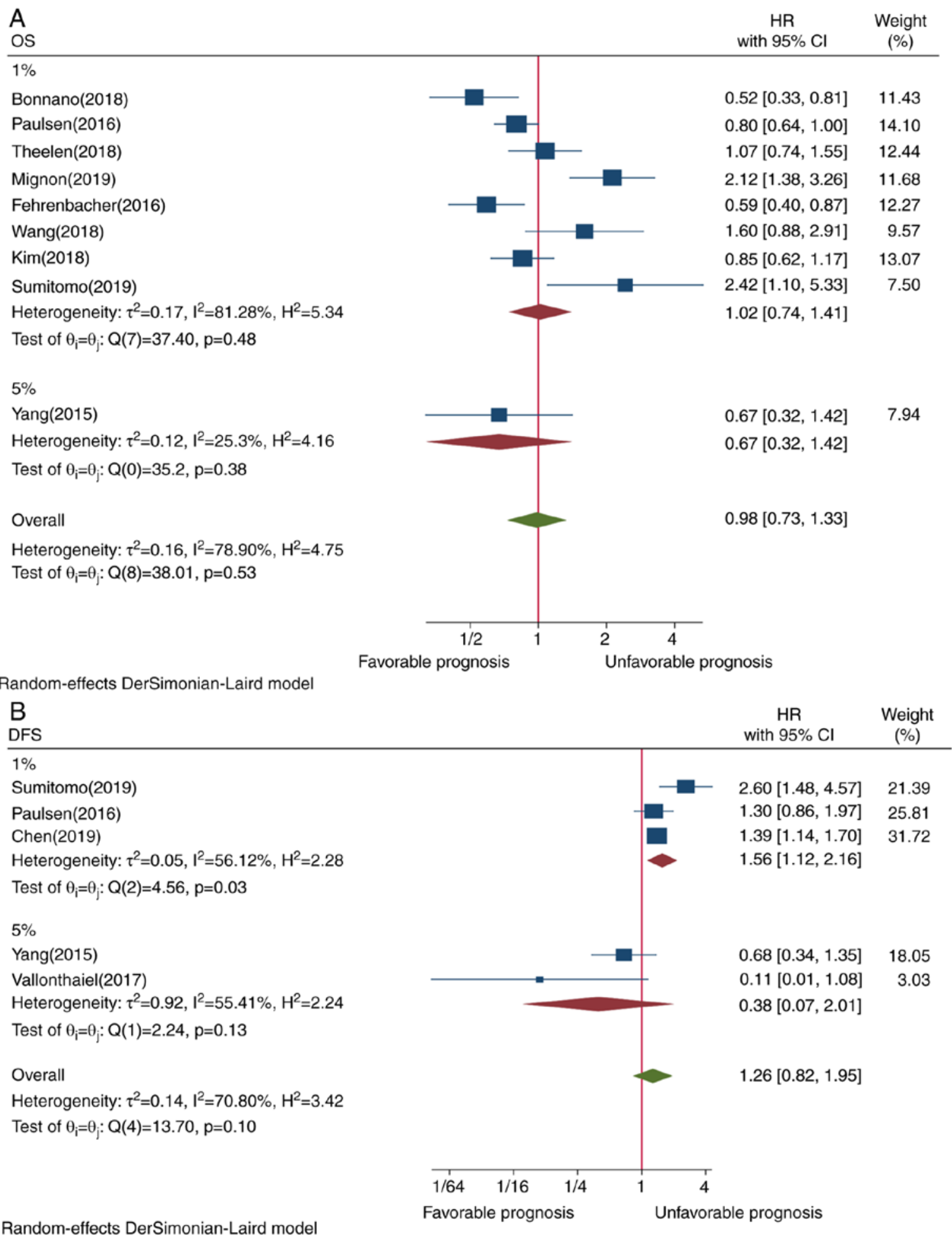

Figure 4. Forest plot presenting the relationship between PD-L1 TIIC and prognosis using the staining cutoff value. (A) OS and (B) DFS for 1 and 5\% cutoff values. PD-L1, programmed cell death ligand 1; TIIC, tumor infiltrating immune cells; OS, overall survival; DFS, disease free survival; HR, hazard ratio; CI, confidence interval.

tumor microenvironment in the subset of cells along with their unique molecular mechanism may greatly affect PD-L1 induction (37) and, in turn, the clinical outcome of the patients. Thus, PD-L1 expression generate differently could respond to therapeutic strategies distinctly (38). On this basis, classifying patients with lung cancer is important for the safety and efficacy of treatment, as well as for improving prognosis.
The results of the present meta-analysis suggest that patients with lung adenocarcinoma with PD-L1-positive expression in TIICs may benefit from anti-PD-L1 treatment. This hypothesis was supported by previous cohort studies demonstrating that PD-L1 overexpression in TIICs predicted response to anti-PD-1/PD-L1 therapy with atezolizumuab $(11,36,39)$. This, in turn, suggests that adding PD-L1 TIIC to the existing 
A

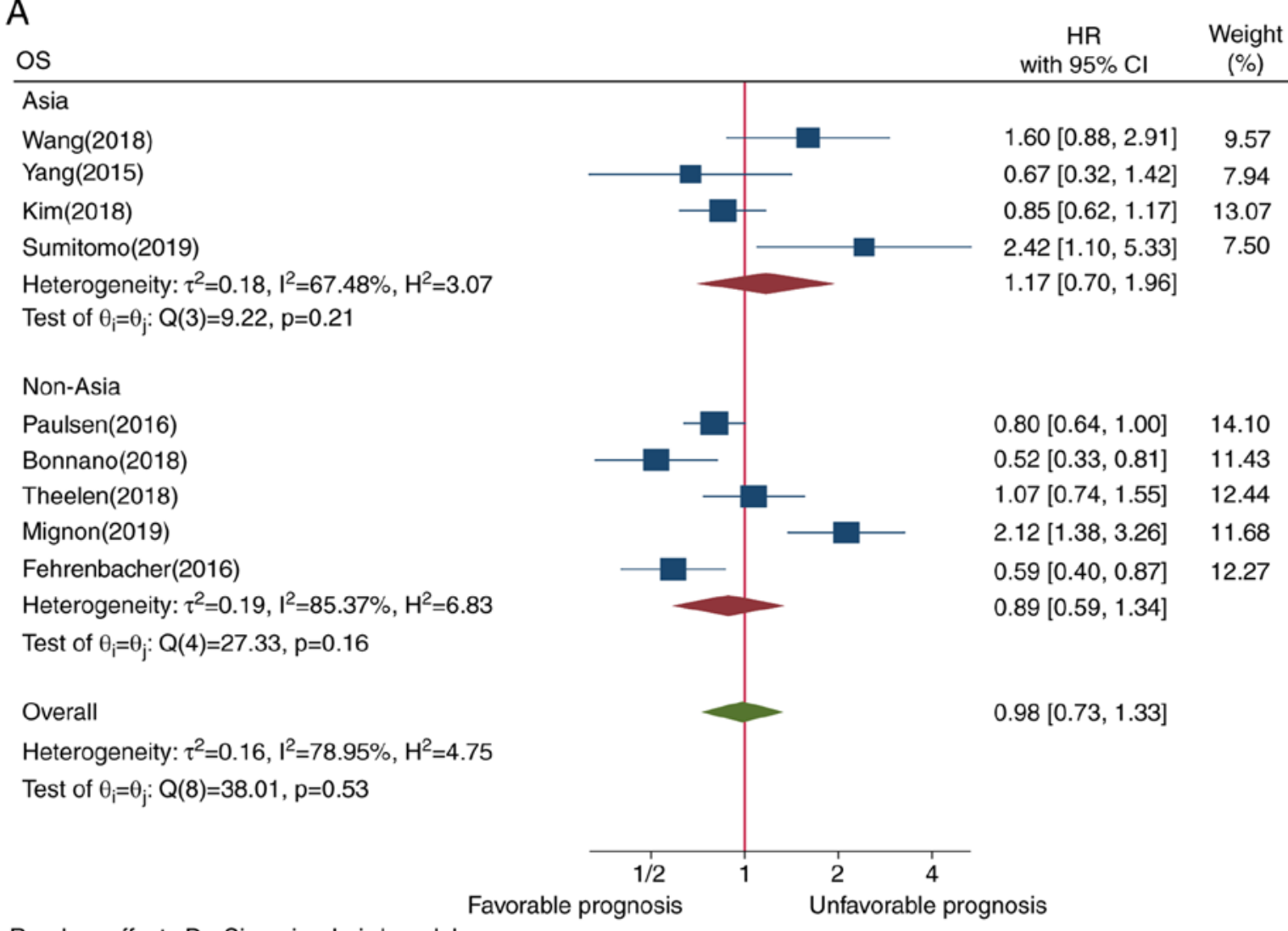

$\mathrm{B}$

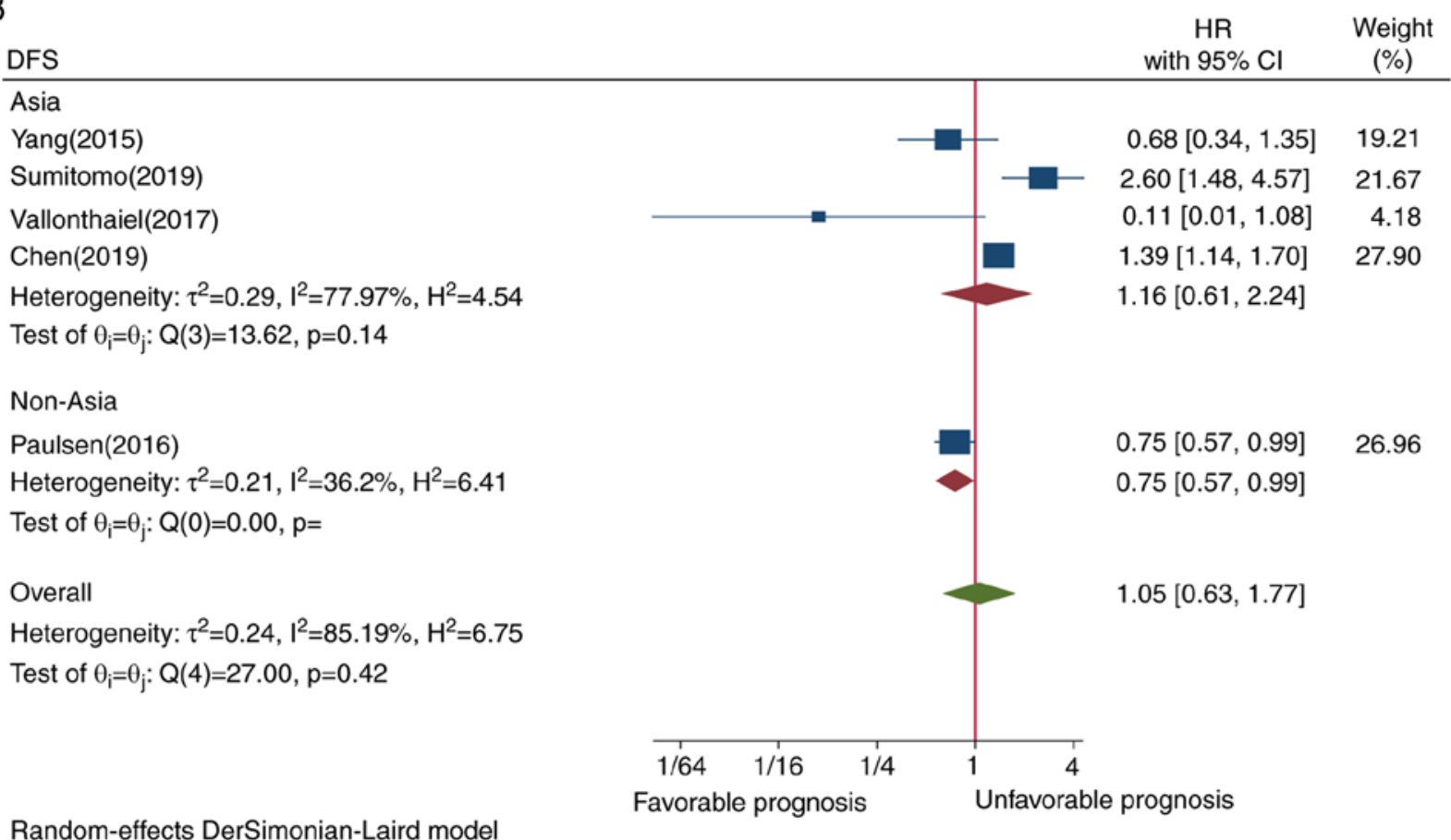

Figure 5. Forest plot presenting the relationship between PD-L1 TIIC and prognosis by ethnicity. (A) OS and (B) DFS. PD-L1, programmed cell death ligand 1; TIIC, tumor infiltrating immune cells; OS, overall survival; DFS, disease free survival; HR, hazard ratio; CI, confidence interval.

PD-L1 tumor cell (TC) in the diagnostic algorithm could help to select patients.

As regards staining localization, there are certain concerns with regard to the challenges in distinguishing membranous from cytoplasmic staining $(19,40)$ and controversies regarding the need to classify the localization to predict prognosis. The results of the present meta-analysis revealed that membrane-only staining tended to predict worse DFS, although the association was not significant. This may be partly due to the fact that, although there may exist variations 


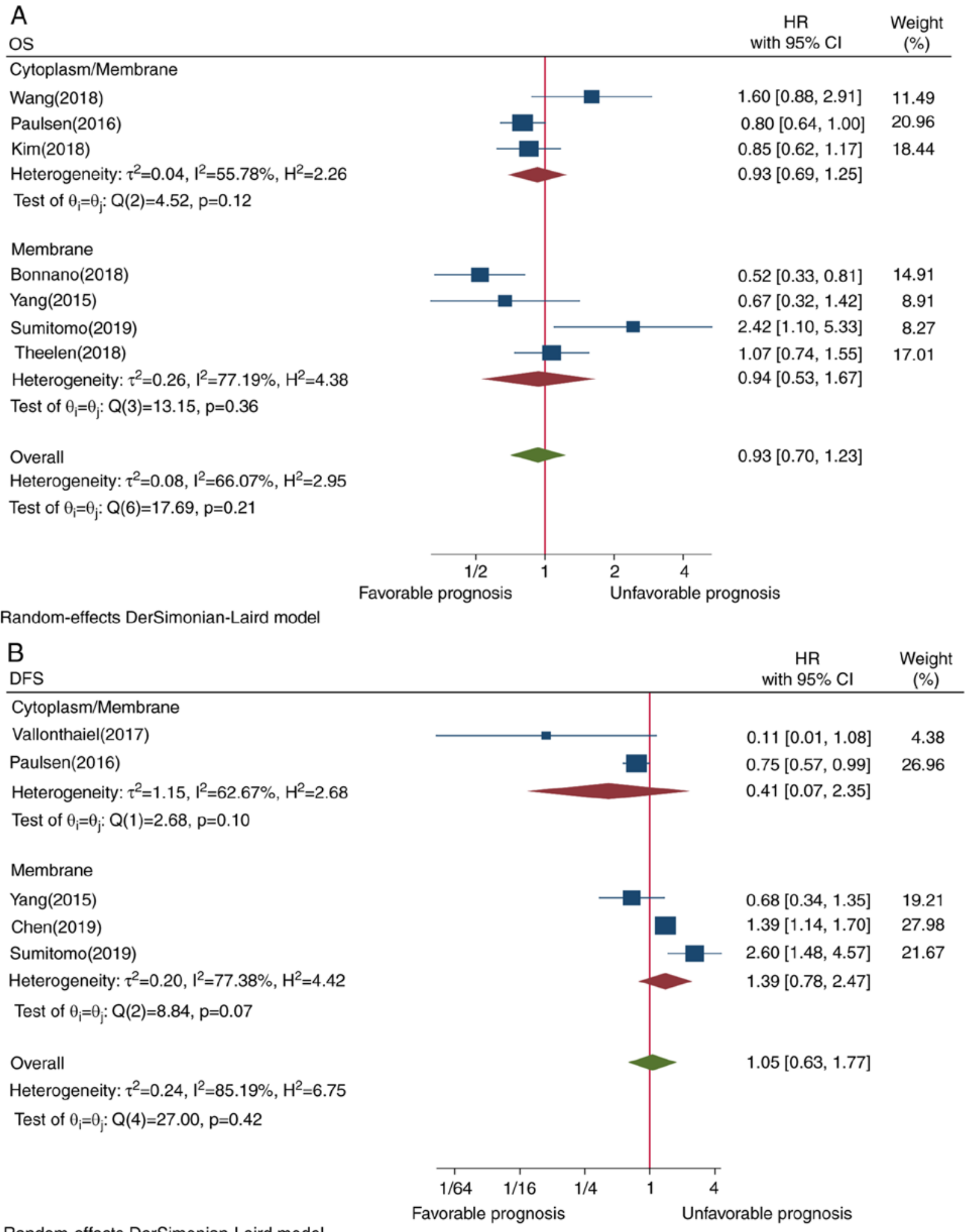

Figure 6. Forest plot presenting the relationship between PD-L1 TIIC and prognosis by staining location. (A) OS and (B) DFS for only-membrane and cytoplasm/membrane staining. PD-L1, programmed cell death ligand 1; TIIC, tumor infiltrating immune cells; OS, overall survival; DFS, disease free survival; $\mathrm{HR}$, hazard ratio; CI, confidence interval.

in staining expression status, the characteristics of PD-L1 IHC assay and staining priority pattern of assays mainly determine prognosis. Previous studies indicate that both the SP142 and E1L3N clones are more specific against intracellular PD-L1 $(40,41)$, while SP142 is less sensitive compared with other assays (42). In other words, antibodies that are directed against the extracellular compartment could have limited influence on other intracellular PD-L1 forms (cytoplasmic and nuclear-PD-L1), which could, to certain extent, affect the efficacy of PD-L1-based immunotherapy (43). By contrast, it 


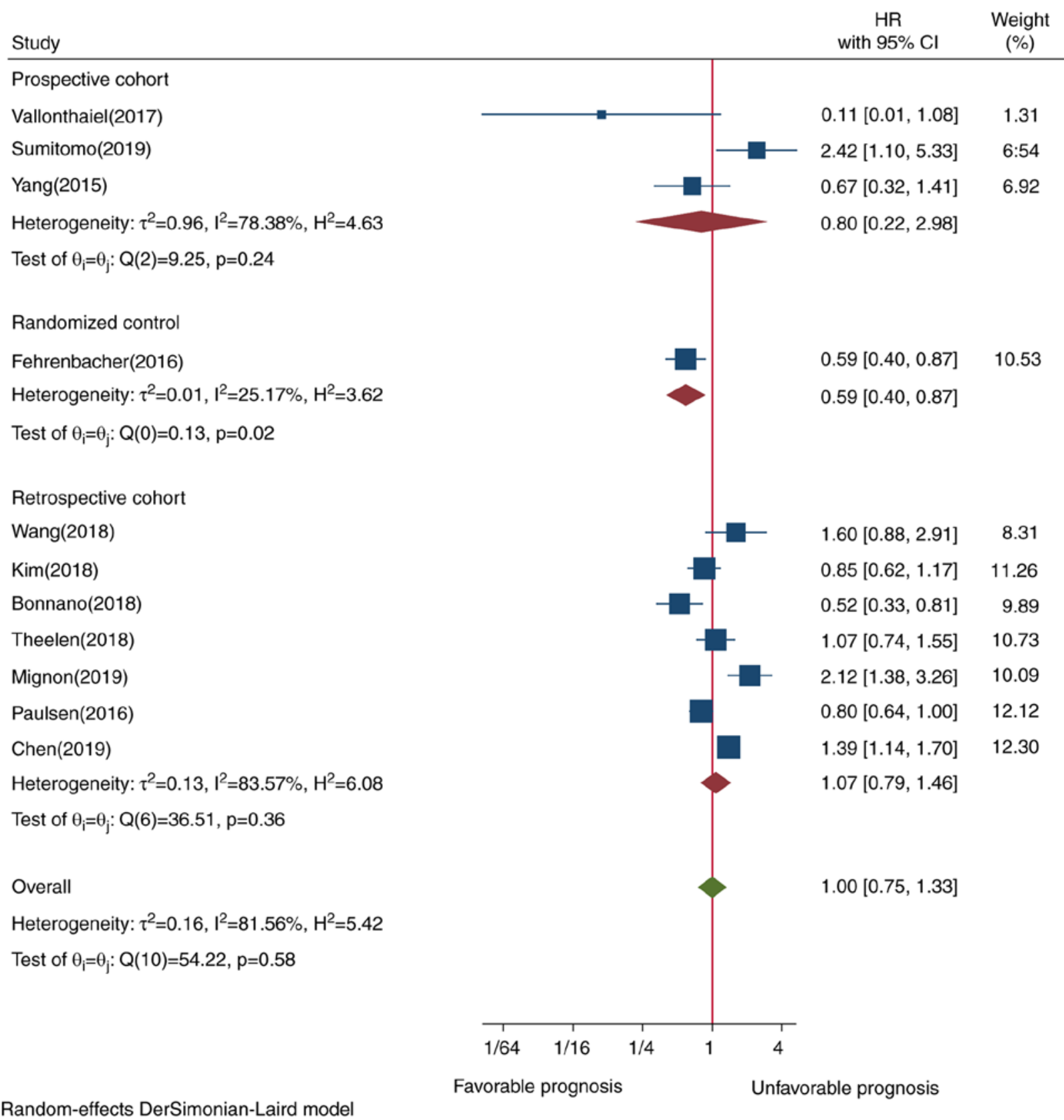

Figure 7. Forest plot presenting the relationship between PD-L1 TIIC and OS by study design. PD-L1, programmed cell death ligand 1; TIIC, tumor infiltrating immune cells; OS, overall survival; DFS, disease free survival; HR, hazard ratio; CI, confidence interval.

was previously reported that specific monoclonal antibodies that recognize PD-L1 variants in the extracellular compartment could also detect PD-L1 determinants retained in the cytoplasm (40). Taken together, these findings suggest that having a detailed knowledge of the functional and structural integrity of membranous and cytoplasmic (mPD-L1/cPD-L1) is important for selecting patients who may benefit from this classification, and to reduce anti-PD-1/PD-L1 therapyassociated toxicity. Large, comprehensive and well-designed studies are required in this field, investigating cytoplasm-and/or membrane-infiltrating immune cells.

Previous cohorts demonstrated that the largest survival benefit was obtained for the highest level of PD-L1 (TC $\geq 50 \%$ or IC $\geq 10 \%$ ) $(11,39)$. However, $\geq 50 \%$ PD-L1 was not included in the present meta-analysis, as the included primary studies were assessed either by 1 or $5 \%$ cutoff value. For cutoff value subgroup analysis, it was reported that $1 \%$, but not 5\%, cutoff value for PD-L1 TIIC was associated with poor DFS. This is partially in agreement with previous meta-analyses $(6,7,44)$. However, there was a contradictory trend when $\geq 1$ or $\geq 5 \%$ staining cutoff value was used for assessing the association of PD-L1 TIIC with the prognosis of patients with cancer. Thus, multi-classification of cutoff values for evaluating PD-L1-positive expression in TIICs may be feasible and reasonable.

The present meta-analysis has certain limitations. First, different research designs, such as observational studies and randomized control studies, were combined. Second, there were differences in the antibody clone used and the scoring criteria. Third, the present study was limited to studies 


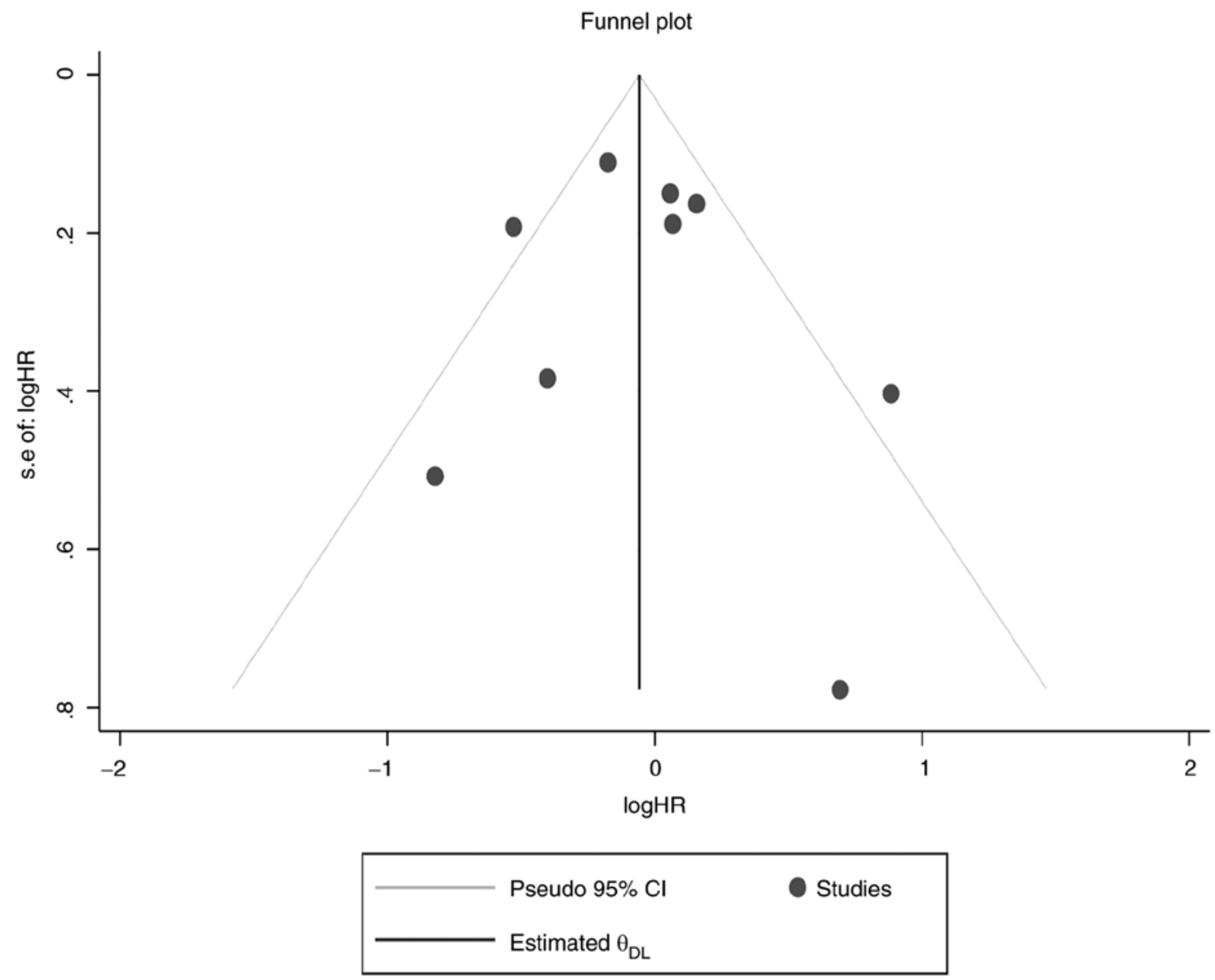

Figure 8. Funnel plot showing to estimate publication bias. HR, hazard ratio.

published in English. Fourth, due to insufficient data, clinicopathological factors on PD-L1 TIIC could not be analyzed. However, the present results may serve as a useful guide for future studies.

In conclusion, based on the present pooled meta-analysis results, positive PD-L1 expression in TIICs was not associated with OS or DFS in the total population of the included studies on patients with lung cancer. However, it was correlated with subtype of lung cancer, since PD-L1 expression in TIICs was associated with worse DFS in patients with lung adenocarcinoma, but with improved OS in patients with lung squamous cell carcinoma. This suggests that adding PD-L1 TIIC to existing PD-L1 TC in the diagnostic algorithm may help with the selection of patients who may benefit from this classification, particularly those with lung adenocarcinoma. However, future large-scale studies are required to verify these findings.

\section{Acknowledgements}

Not applicable.

\section{Funding}

The research was supported by the Joint fund of Hubei Health and Family Planning Commission (grant. no. WJ2018H0018).

\section{Availability of data and materials}

The datasets used and/or analyzed during the current study are available from the corresponding author on reasonable request.

\section{Authors' contributions}

BAB and GY conceived and designed the current study, acquired and analyzed the data, and revised the manuscript. TW conceived and designed the current study, analyzed the data and revised the manuscript. BAB and GY confirm the authenticity of all the raw data. All authors read and approved the final manuscript.

\section{Ethics approval and consent to participate}

Not applicable.

\section{Patient consent for publication}

Not applicable.

\section{Competing interest}

The authors declare that they have no competing interests. 


\section{References}

1. Bray F, Ferlay J, Soerjomataram I, Siegel RL, Torre LA and Jemal A: Global cancer statistics 2018: GLOBOCAN estimates of incidence and mortality worldwide for 36 cancers in 185 countries. CA Cancer J Clin 68: 394-424, 2018.

2. Luo D, Carter KA, Miranda D and Lovell JF: Chemophototherapy: An emerging treatment option for solid tumors. Adv Sci (Weinh) 4: 1600106, 2016.

3. Shukuya T and Carbone DP: Predictive markers for the efficacy of Anti-PD-1/PD-L1 antibodies in lung cancer. J Thorac Oncol 11: 976-988, 2016

4. Aguiar PN Jr, Santoro IL, Tadokoro H, de Lima Lopes G, Filardi BA, Oliveira P, Mountzios G and de Mello RA: The role of PD-L1 expression as a predictive biomarker in advanced non-small-cell lung cancer: A network meta-analysis. Immunotherapy 8: 479-488, 2016.

5. Chen DS, Irving BA and Hodi FS: Molecular pathways: Next-generation immunotherapy-inhibiting programmed death-ligand 1 and programmed death-1. Clin Cancer Res 18 6580-6587, 2012.

6. Zhao T, Li C, Wu Y and Li B: Prognostic value of PD-L1 expression in tumor infiltrating immune cells in cancers: A meta-analysis. PLoS One 12: e0176822, 2017.

7. Li H, Xu Y, Wan B, Song Y, Zhan P, Hu Y, Zhang Q, Zhang F, Liu H, Li T, et al: The clinicopathological and prognostic significance of PD-L1 expression assessed by immunohistochemistry in lung cancer: A meta-analysis of 50 studies with 11,383 patients. Transl Lung Cancer Res 8: 429-449, 2019.

8. Wang A, Wang HY, Liu Y, Zhao MC, Zhang HJ, Lu ZY, Fang YC, Chen XF and Liu GT: The prognostic value of PD-L1 expression for non-small cell lung cancer patients: A meta-analysis. Eur J Surg Oncol 41: 450-456, 2015.

9. Zhang M, Li G, Wang Y, Wang Y, Zhao S, Haihong P, Zhao H and Wang Y: PD-L1 expression in lung cancer and its correlation with driver mutations: A meta-analysis. Sci Rep 7: 10255, 2017.

10. Herbst RS, Soria JC, Kowanetz M, Fine GD, Hamid O, Gordon MS, Sosman JA, McDermott DF, Powderly JD, Gettinger SN, et al: Predictive correlates of response to the anti-PD-L1 antibody MPDL3280A in cancer patients. Nature 515: 563-567, 2014.

11. Fehrenbacher L,Spira A, Ballinger M,Kowanetz M, Vansteenkiste J, Mazieres J, Park K, Smith D, Artal-Cortes A, Lewanski C, et al: Atezolizumab versus docetaxel for patients with previously treated non-small-cell lung cancer (POPLAR): A multicentre, open-label, phase 2 randomised controlled trial. Lancet 387: 1837-1846, 2016.

12. Liberati A, Altman DG, Tetzlaff J, Mulrow C, Gotzsche PC, Loannidis JPA, Clarke M, Devereaux PJ, Kleijnen J and Moher D: The PRISMA statement for reporting systematic reviews and meta-analyses of studies that evaluate healthcare interventions: Explanation and elaboration. BMJ 339: b2700, 2009.

13. Rohatgi A: WebPlotDigitizer, https://automeris.io/ WebPlotDigitizer. Accessed November, 2020.

14. Yang CY, Lin MW, Chang YL, Wu CT and Yang PC: Programmed cell death-ligand 1 expression is associated with a favourable immune microenvironment and better overall survival in stage pulmonary squamous cell carcinoma. Eur J Cancer 57: 91-103, 2016.

15. Theelen WSME, Kuilman T, Schulze K, Zou W, Krijgsman O, Peters DDGC, Cornelissen S, Monkhorst K, Sarma P, Sumiyoshi T, et al: Absence of PD-L1 expression on tumor cells in the context of an activated immune infiltrate may indicate impaired IFN $\gamma$ signaling in non-small cell lung cancer. PLoS One 14: e0216864, 2019.

16. Mignon S, Willard-Gallo K, Van den Eynden G, Salgado R, Decoster L, Marien KM, Vansteenkiste JF, Teugels E and De Grève J: The relationship between tumor-infiltrating lymphocytes, PD-L1 expression, driver mutations and clinical outcome parameters in non-small cell lung cancer adenocarcinoma in patients with a limited to no smoking history. Pathol OncolRes 26: 1221-1228, 2020.

17. Vallonthaiel AG, Malik PS, Singh V, Kumar V, Kumar S, Sharma MC, Mathur S, Arava S, Guleria R and Jain D: Clinicopathologic correlation of programmed death ligand-1 expression in non-small cell lung carcinomas: A report from India. Ann Diagn Pathol 31: 56-61, 2017.

18. Chen L, Cao MF, Zhang X, Dang WQ, Xiao JF, Liu Q, Tan YH, Tan YY, Xu YY, Xu SL, et al: The landscape of immune microenvironment in lung adenocarcinoma and squamous cell carcinoma based on PD-L1 expression and tumor-infiltrating lymphocytes. Cancer Med 8: 7207-7218, 2019.
19. Paulsen EE, Kilvaer TK, Khanehkenari MR,Al-Saad S,Hald SM, Andersen S, Richardsen E, Ness N, Busund LT, Bremnes RM and Donnem T: Assessing PDL-1 and PD-1 in non-small cell lung cancer: A novel immunoscore approach. Clin Lung Cancer 18: 220-233.e8, 2017.

20. Sumitomo R, Hirai T, Fujita M, Murakami H, Otake Y and Huang CL: PD-L1 expression on tumor-infiltrating immune cells is highly associated with M2 TAM and aggressive malignant potential in patients with resected non-small cell lung cancer. Lung Cancer 136: 136-144, 2019.

21. Wang H, Li Z, Dong B, Sun W, Yang X, Liu R, Zhou L, Huang X, Jia L and Lin D: Prognostic significance of PD-L1 expression and $\mathrm{CD}^{+} \mathrm{T}$ cell infiltration in pulmonary neuroendocrine tumors. Diagn Pathol 13: 30, 2018.

22. Kim HS, Lee JH, Nam SJ, Ock CY, Moon JW, Yoo CW, Lee GK and Han JY: Association of PD-L1 expression with tumor-infiltrating immune cells and mutation burden in high-grade neuroendocrine carcinoma of the lung. J Thorac Oncol 13: 636-648, 2018.

23. Bonanno L, Pavan A, Dieci MV, Di Liso E, Schiavon M, Comacchio G, Attili I, Pasello AG, Calabrese F, Rea F, et al: The role of immune microenvironment in small-cell lung cancer: Distribution of PD-L1 expression and prognostic role of FOXP3-positive tumour infiltrating lymphocytes. Eur J Cancer 101: 191-200, 2018.

24. Song P, Guo L, Li W, Zhang F, Ying J and Gao S: Clinicopathologic correlation with expression of PD-L1 on both tumor cells and tumor-infiltrating immune cells in patients with non-small cell lung cancer. J Immunother 42: 23-28, 2019.

25. Huang W, Ran R, Shao B and Li H: Prognostic and clinicopathological value of PD-L1 expression in primary breast cancer: A meta-analysis. Breast Cancer Res Treat 178: 17-33, 2019.

26. Wang BC, Zhang ZJ, Fu C and Wang C: Efficacy and safety of anti-PD-1/PD-L1 agents vs. chemotherapy in patients with gastric or gastroesophageal junction cancer: A systematic review and meta-analysis. Medicine (Baltimore) 98: e18054, 2019.

27. Huang $Y$ and Shen A: The prediction potential of neutrophil-to-lymphocyte ratio for the therapeutic outcomes of programmed death receptor-1/programmed death ligand 1 inhibitors in non-small cell lung cancer patients: A meta-analysis. Medicine (Baltimore) 99: e21718, 2020.

28. Wang C, Yu X and Wang W: A meta-analysis of efficacy and safety of antibodies targeting PD-1/PD-L1 in treatment of advanced nonsmall cell lung cancer. Medicine (Baltimore) 95: e5539, 2016.

29. Li JH, Ma WJ, Wang GG, Jiang X, Chen X, Wu L, Liu ZS, Zeng XT, Zhou FL and Yuan YF: Clinicopathologic significance and prognostic value of programmed cell death ligand 1 (PD-L1) in patients with hepatocellular carcinoma: A meta-analysis. Front Immunol 9: 2077, 2018

30. Kim Y, Wen X, Cho NY and Kang GH: Intratumoral immune cells expressing PD-1/PD-L1 and their prognostic implications in cancer: A meta-analysis. Int J Biol Markers: May 1, 2018 (Epub ahead of print). doi: 10.1177/1724600818770941.

31. Dix Junqueira Pinto G, de Souza Viana L, Scapulatempo Neto C and Vicente Serrano S: Evaluation of PD-L1 expression in tumor tissue of patients with lung carcinoma and correlation with clinical and demographic data. J Immunol Res 2016: 9839685, 2016.

32. Pezzuto A, Cappuzzo F, D'Arcangelo M, Ciccozzi M, Navarini L, Guerrini S, Ricci A, D'Ascanio M and Carico E: Prognostic value of p16 protein in patients with surgically treated non-small cell lung cancer; Relationship with Ki-67 and PD-L1. Anticancer Res 40: 983-990, 2020.

33. Sun C, Zhang L, Zhang W, Liu Y, Chen B, Zhao S, Li W, Wang L, Ye L, Jia K, et al: Expression of PD-1 and PD-L1 on tumor-infiltrating lymphocytes predicts prognosis in patients with small-cell lung cancer. Onco Targets Ther 13: 6475-6483, 2020.

34. Kim HR, Ha SJ, Hong MH, Heo SJ, Koh WY, Choi EC, Kim EK, Pyo KH, Jung I, Seo D, et al: PD-L1 expression on immune cells, but not on tumor cells, is a favorable prognostic factor for head and neck cancer patients. Sci Rep 6: 36956, 2016.

35. Ma J, Chi D, Wang Y, Yan Y, Zhao S, Liu H, Jing J, Pu H and Zhang M: Prognostic value of PD-L1 expression in resected lung adenocarcinoma and potential molecular mechanisms. J Cancer 9: 3489-3499, 2018

36. Cha YJ, Kim HR, Lee CY, Cho BC and Shim HS: Clinicopathological and prognostic significance of programmed cell death ligand-1 expression in lung adenocarcinoma and its relationship with p53 status. Lung cancer 97: 73-80, 2016.

37. Chen S, Crabill GA, Pritchard TS, McMiller TL, Wei P, Pardoll DM, Pan F and Topalian SL: Mechanisms regulating PD-L1 expression on tumor and immune cells. J Immunother Cancer 7: 305, 2019. 
38. Wei Y, Zhao Q, Gao Z, Lao XM, Lin WM, Chen DP, Mu M, Huang CX, Liu ZY, Li B, et al: The local immune landscape determines tumor PD-L1 heterogeneity and sensitivity to therapy. J Clin Invest 129: 3347-3360, 2019.

39. Rittmeyer A, Barlesi F, Waterkamp D, Park K, Ciardiello F, von Pawel J, Gadgeel SM, Hida T, Kowalski DM, Dols MC, et al: Atezolizumab versus docetaxel in patients with previously treated non-small-cell lung cancer (OAK): A phase 3, open-label, multicentre randomised controlled trial. Lancet 389: 255-265, 2017.

40. Mahoney KM, Sun H, Liao X, Hua P, Callea M, Greenfield EA, Hodi FS, Sharpe AH, Signoretti S, Rodig SJ and Freeman GJ: PD-L1 Antibodies to its cytoplasmic domain most clearly delineate cell membranes in immunohistochemical staining of tumor cells. Cancer Immunol Res 3: 1308-1315, 2015.

41. Mino-Kenudson M: Programmed cell death ligand-1 (PD-L1) expression by immunohistochemistry: Could it be predictive and/or prognostic in non-small cell lung cancer? Cancer Biol Med 13: 157-170, 2016.
42. Kintsler S, Cassataro MA, Drosch M, Holenya P, Knuechel R and Braunschweig T: Expression of programmed death ligand (PD-L1) in different tumors. Comparison of several current available antibody clones and antibody profiling. Ann Diagn Pathol 41: 24-37, 2019.

43. Wu Y, Chen W, Xu ZP and Gu W: PD-L1 distribution and perspective for cancer immunotherapy-blockade, knockdown, or inhibition. Front Immunol 10: 2022, 2019.

44. Abdel-Rahman O: Correlation between PD-L1 expression and outcome of NSCLC patients treated with anti-PD-1/PD-L1 agents: A meta-analysis. Crit Rev Oncol Hematol 101: 75-85, 2016.

(i) (9) This work is licensed under a Creative Commons Attribution-NonCommercial-NoDerivatives 4.0 International (CC BY-NC-ND 4.0) License. 